\title{
Relationships between GPS-signal propagation errors and EISCAT observations
}

\author{
N. Jakowski, E. Sardon, E. Engler, A. Jungstand, D. Klähn \\ DLR e.V., Fernerkundungsstation Neustrelitz, Kalkhorstweg 53, Germany \\ Received: 4 March 1996/Revised: 10 June 1996/Accepted: 11 June 1996
}

\begin{abstract}
When travelling through the ionosphere the signals of space-based radio navigation systems such as the Global Positioning System (GPS) are subject to modifications in amplitude, phase and polarization. In particular, phase changes due to refraction lead to propagation errors of up to $50 \mathrm{~m}$ for single-frequency GPS users. If both the L1 and the L2 frequencies transmitted by the GPS satellites are measured, first-order range error contributions of the ionosphere can be determined and removed by difference methods. The ionospheric contribution is proportional to the total electron content (TEC) along the ray path between satellite and receiver. Using about ten European GPS receiving stations of the International GPS Service for Geodynamics (IGS), the TEC over Europe is estimated within the geographic ranges $-20^{\circ} \leq \lambda \leq 40^{\circ} \mathrm{E}$ and $32.5^{\circ} \leq \phi \leq 70^{\circ} \mathrm{N}$ in longitude and latitude, respectively. The derived TEC maps over Europe contribute to the study of horizontal coupling and transport processes during significant ionospheric events. Due to their comprehensive information about the high-latitude ionosphere, EISCAT observations may help to study the influence of ionospheric phenomena upon propagation errors in GPS navigation systems. Since there are still some accuracy limiting problems to be solved in TEC determination using GPS, data comparison of TEC with vertical electron density profiles derived from EISCAT observations is valuable to enhance the accuracy of propagation-error estimations. This is evident both for absolute TEC calibration as well as for the conversion of ray-path-related observations to vertical TEC. The combination of EISCAT data and GPS-derived TEC data enables a better understanding of large-scale ionospheric processes.
\end{abstract}

\section{Introduction}

Satellite radio beacon signals have been widely used in exploring the temporal and spatial structure of the ionosphere since the launch of Sputnik I (e.g. Davies, 1991). Recently, space-based radio navigation systems such as the US Global Positioning System (GPS) offer new opportunities for studying the ionosphere on a global scale (e.g. Coco, 1991; Wilson et al., 1995; Zarraoa and Sardon 1996). This is possible because GPS satellites transmit coherent dual-frequency signals in the L-band, low enough to measure a significant ionospheric contribution.

On the other hand, the ionospheric refraction cannot be ignored at these frequencies in precise navigation and positioning systems. Single-frequency GPS users have to take into account ionospheric-induced propagation errors up to $50 \mathrm{~m}$ depending on the total electron content (TEC) along the ray path.

Although the first-order ionospheric effect can in principle be measured and therefore removed in dual-frequency satellite positioning systems by differencing measurements, there remain a number of unresolved questions and problems related to the ionospheric behaviour; in particular, the auroral and polar ionosphere may cause severe distortions in GPS receivers (Bishop, 1994). So it is evident that EISCAT measurements and their interpretation can help to improve the accuracy in satellite positioning. On the other hand, GPS measurements provide a powerful tool for large-scale ionospheric studies. If both observation areas overlap (see Fig. 1), direct correlation studies should be possible.

\section{TEC measurements by means of GPS}

GPS satellites transmit two coherent frequencies in the L-band at $f_{1}=1575.4 \mathrm{MHz}\left(\mathrm{L}_{1}\right)$ and at $f_{2}=1227.6 \mathrm{MHz}$ $\left(\mathrm{L}_{2}\right)$. The $\mathrm{L}_{1}$ frequency is modulated by a public Coarse/ Acquisition code $(\mathrm{C} / \mathrm{A})$ with an effective wavelength of $300 \mathrm{~m}$. Both carrier frequencies are modulated by a 


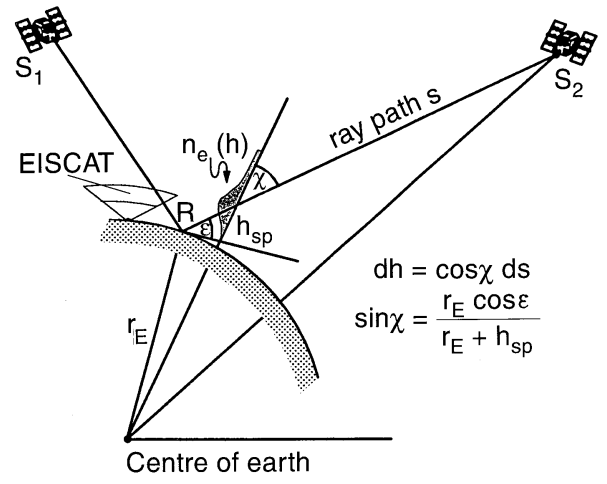

Fig. 1. Scheme of the ray-path geometry between GPS satellites $S_{1,2}$ and a receiver $\mathrm{R}$. The mapping function $M(\varepsilon)$ is related to the zenith angle $\chi$ of the ray path $s$ at the pierce point with the assumed ionospheric shell at the height $h_{s p}$

precise code ( $\mathrm{P}$ or $\mathrm{Y}$ ) with an effective wavelength of approximately $30 \mathrm{~m}$. For unauthorized users the accuracy of GPS can be degraded by selective availability (SA) or antispoofing (AS). In case of SA, the accuracy obtained from the C/A code is limited to about $100 \mathrm{~m}$ by artificially introduced errors in the navigation message. If the encrypted Y code is turned on (AS), only military receivers can utilize the much more precise code measurements.

To determine the range between satellite and receiver, the time-delay of the pseudorandom-noise code sequences of the received signal is measured with rather high accuracy by cross-correlation with the receiver-generated code sequence. However, these measurements are generally biased by a number of errors, such as clock offsets on board satellites as well as on ground, tropospheric, ionospheric and multipath effects. So the measured ranges are referred to as pseudoranges $p$ which may be written in the form:

$p=\rho+\mathrm{c}(d t-d T)+d_{I}+d_{T}+d_{M P}+d q+d Q+\varepsilon_{p}$,

where $\rho$ is the geometric range between satellite and receiver, $\mathrm{c}$ is the velocity of light in vacuum, $d t$ is the offset of satellite clock, $d T$ is the offset of receiver clock, $d_{I}$ is the ionospheric delay, $d_{T}$ is the tropospheric delay, $d_{M P}$ is the effect of multipath on pseudorange, $d q$ is the instrumental group delay bias of the satellite, $d Q$ is the instrumental group delay bias of the receiver and $\varepsilon_{p}$ is the random error on pseudorange.

When taking into account the refractive index of the ionospheric plasma at L-band frequencies the ionospheric contribution $d_{I}$ may be written as:

$d_{I}=\frac{K}{f^{2}} \int n_{e} d s$,

where $n_{e}$ is the electron density along the ray path $s$ and $K=40.3 \mathrm{~m}^{3} \mathrm{~s}^{-1}$.

Since $d_{I}$ is frequency dependent, pseudorange differences between $\mathrm{L}_{1}$ and $\mathrm{L}_{2}$ signals cancel out the unknown range $\rho$, the clock offsets and the tropospheric error in Eq. 1 and provide an expression for TEC $=\int n_{e} d s$. But unfortunately the differential instrumental biases and multipath terms do not compensate. So the TEC estima-

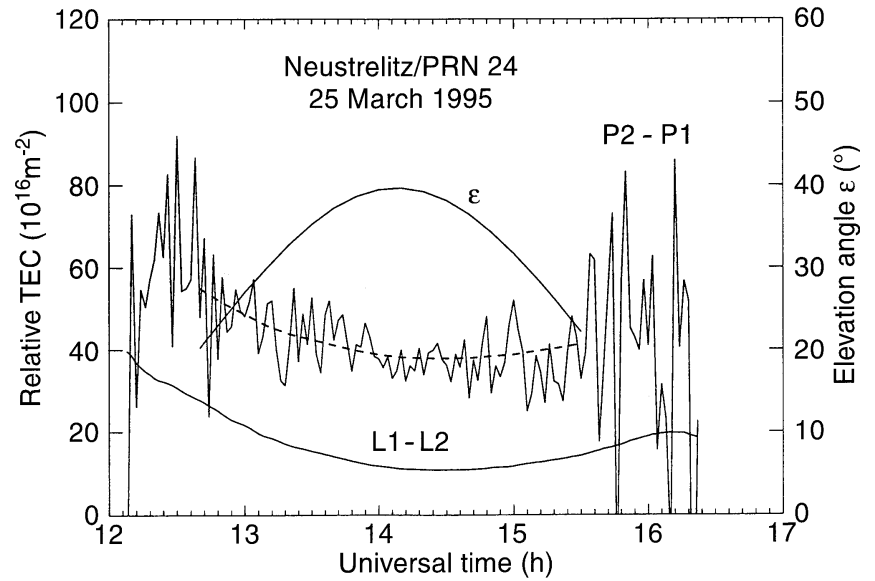

Fig. 2. Differential measurements of pseudorange $\left(\mathrm{p}_{2}-\mathrm{p}_{1}\right)$ and carrier phase $\left(\mathrm{L}_{1}-\mathrm{L}_{2}\right)$ compared with the elevation angle $(\varepsilon)$. The smooth carrier phases are levelled to the noisy pseudorange phases for elevation angles greater than $20^{\circ}$

tion is strongly coupled with the estimation of instrumental delays.

As shown in Fig. 2, the differential pseudorange signal $p_{2}-p_{1}$ is strongly affected by multipath, especially at low elevation angles. Since the fluctuations may exceed the expected TEC values, TEC estimations based only on pseudorange differences are rather uncertain.

The carrier phases can be described in a similar way as written in Eq. 1 for pseudoranges. However, due to their much shorter wavelength the multipath effect practically disappears, thus providing rather smooth data which are uncertain in absolute scale by multiples of wavelengths. To match the absolute level of the pseudoranges, the much more precise carrier-phase data are then adjusted by a constant. These levelled phase data are then used for further processing.

Assuming a second-order polynomial approximation for TEC over each receiving GPS station, the differential instrumental biases and TEC are estimated by means of a Kalman filter (Sardon et al., 1994) during a 24-h run for each satellite-receiver combination. During this time the biases are assumed to be constant.

This TEC estimation procedure reveals TEC data measured along permanently changing satellite links. To obtain normalized data, the slant $\mathrm{TEC}_{\mathrm{s}}$ data are converted to the vertical $\mathrm{TEC}_{\mathrm{v}}$ data by a mapping function $M(\varepsilon)$ which is in general defined by:

$M(\varepsilon)=\mathrm{TEC}_{\mathrm{s}} / \mathrm{TEC}_{\mathrm{v}}$.

For a single-layer approximation of the ionosphere (Fig. 1) we obtain:

$M(\varepsilon)=\frac{1}{\sqrt{1-\left(\frac{r_{E} \cos \varepsilon}{r_{E}+h_{s p}}\right)^{2}}}$,

where $\varepsilon$ is the elevation angle, $r_{E}$ is the Earth radius and $h_{s p}$ is the height of the assumed ionospheric layer at the subionospheric point SP. Taking into account simulation calculations with realistic electron density profiles, the 


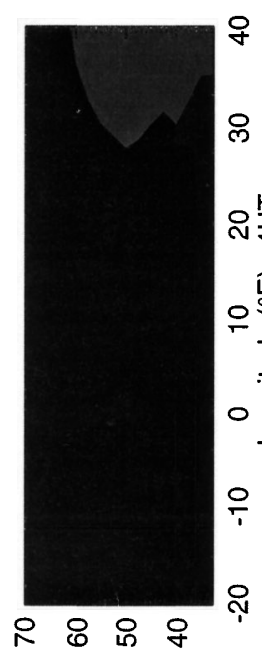

(No) өpn!!ฺ 7

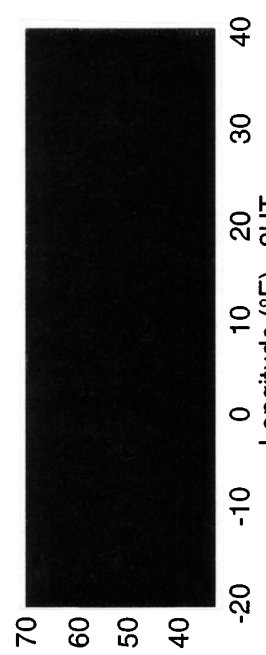

(No) epnџ!ฺe

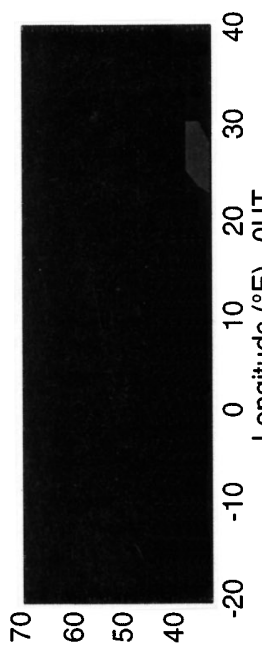

(No) өpn!!ฺ 7

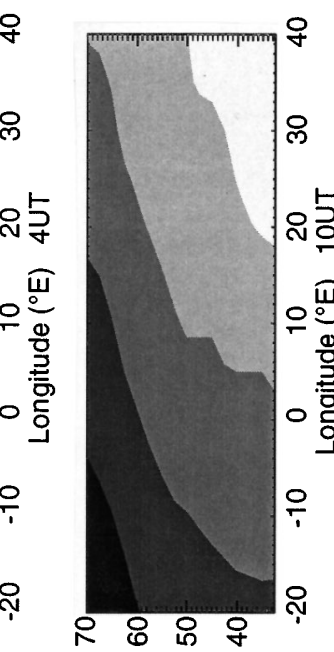

(No) әpn!!!eา

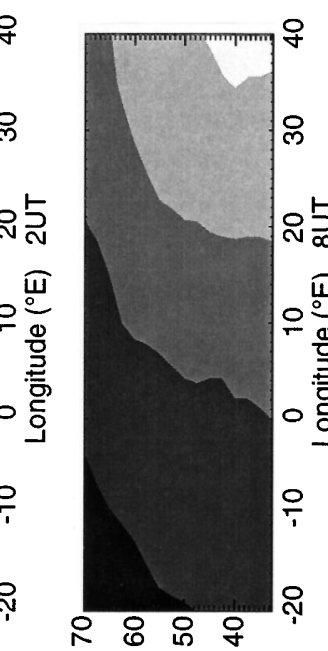

(No) өpn!!ฺe

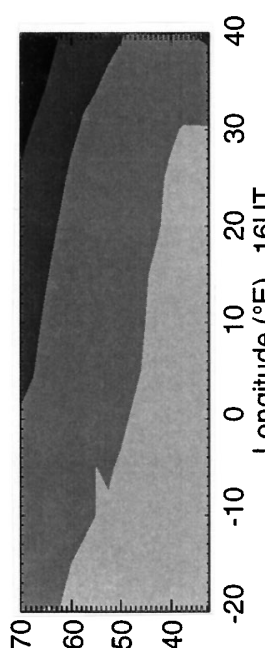

(No) әpn!!̣e 7
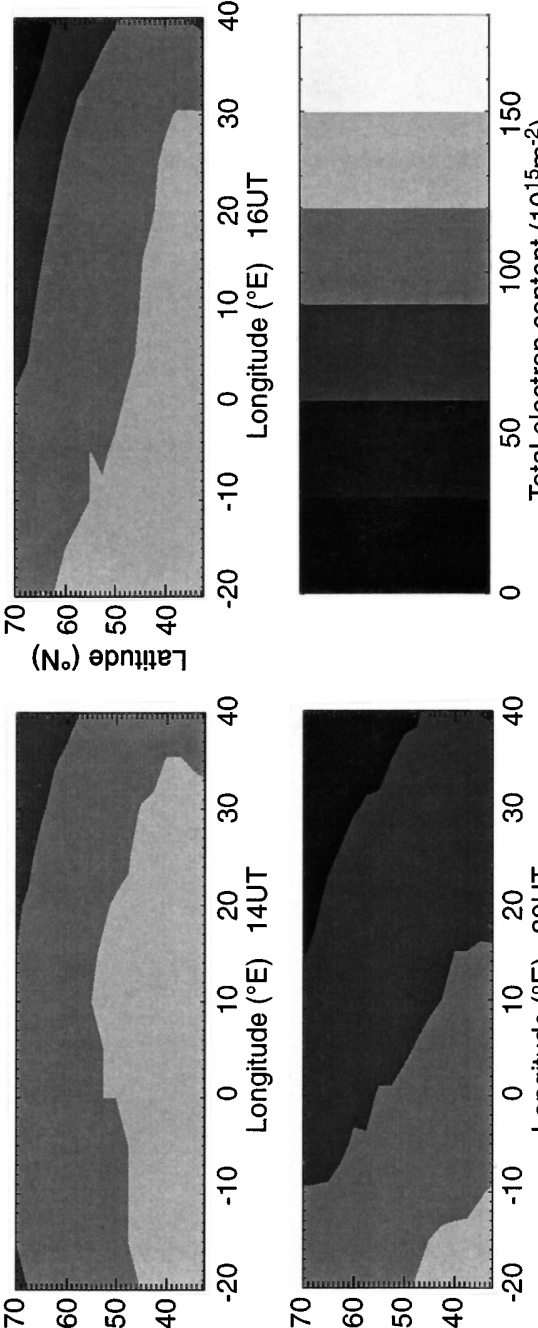

(No) әpn!ฺ̣e

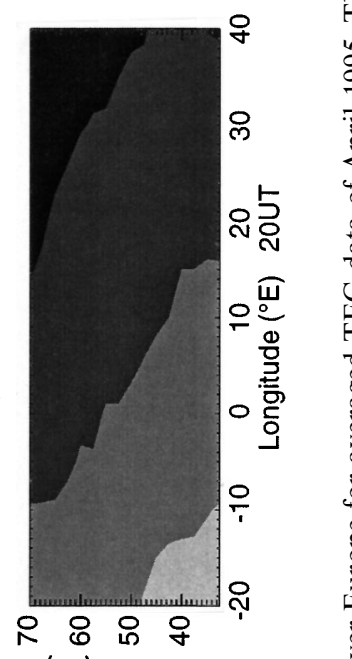

(No) әpnџ!ฺา

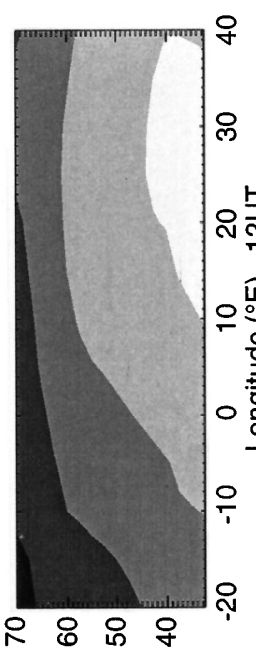

(No) әрnษ!!e 7

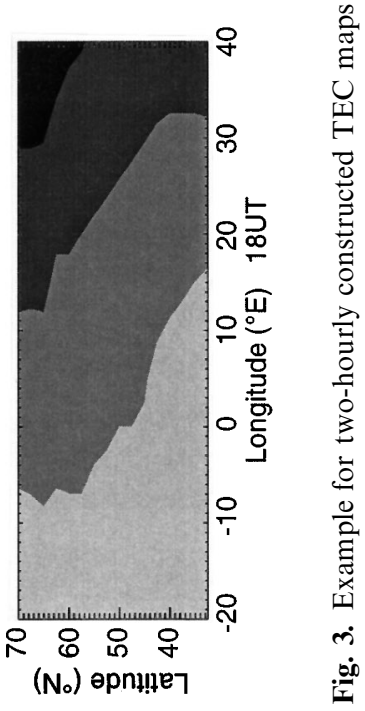




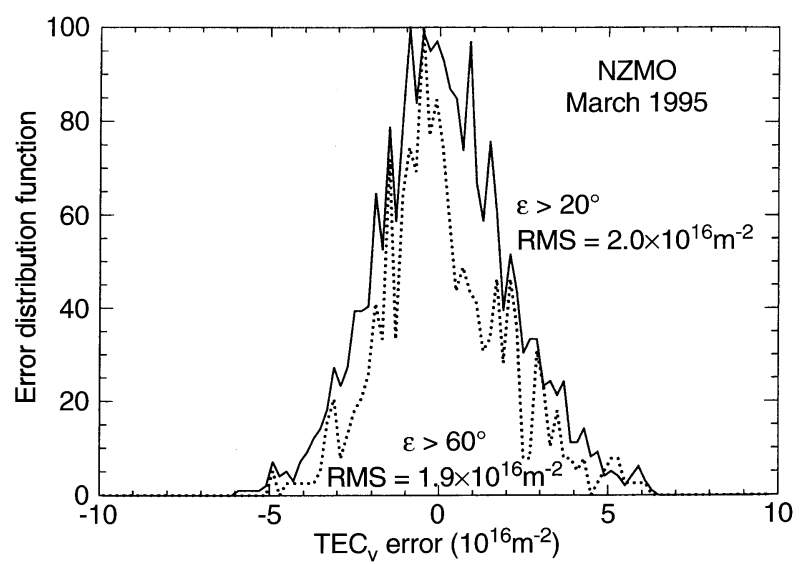

Fig. 4. TEC reconstruction error distribution function for differences between TEC-map values and TEC values measured by the GPS station Neustrelitz which does not contribute to the TEC maps. The analysis includes approximately $2000-3000$ data points from March 1995

height $h_{s p}$ of the ionospheric shell is fixed at $h_{s p}=400 \mathrm{~km}$. After reducing the measured slant TEC data to the vertical-electron-content data at the subionospheric points, regional $\mathrm{TEC}_{\mathrm{v}}$ maps may be constructed. Following Jakowski and Jungstand (1994) this is done by combining a regional TEC model (NTCM1) with actual GPS measurements over Europe. The empirical TEC model is based on numerous Faraday rotation observations carried out at linearly polarized VHF signals transmitted by geostationary satellites such as ATS-6, SIRIO, SMS and GOES types (e.g. Jakowski and Paasch, 1984).

In correspondence with the subionospheric traces of GPS signals receivable at DLR Neustrelitz, the area in view covers the geographic ranges $32.5^{\circ} \leq \varphi \leq 70^{\circ} \mathrm{N}$ and $20.0^{\circ} \leq \lambda \leq 60^{\circ} \mathrm{E}$ in latitude and longitude, respectively. The pixel size of the map grid is defined as $2.5^{\circ} \times 5^{\circ}$ in latitude and longitude, respectively, resulting in 272 grid points.

The NTCM1 model takes into account basic relationships between solar radiation and diurnal and seasonal variations according to:

$\mathrm{TEC}=\sum_{i=1}^{5} \sum_{j=l}^{3} \sum_{k=1}^{2} \sum_{l=1}^{2} H_{i}(h) Y_{j}(d) L_{k}(\varphi, \lambda, h, d) \mathrm{S}_{1}(\mathrm{~F} 10)$,

where $H_{i}(h)$ denotes the diurnal variation, $Y_{j}(d)$ denotes the annual variation, $L_{k}(\varphi, \lambda, h, d)$ characterizes the solar zenith angle dependence and $S_{1}(F 10)$ denotes the solar activity dependence. The corresponding 60 coefficients were determined by least square fits to the observational data with RMS deviations from monthly averages of $5 \times 10^{16} \mathrm{~m}^{-2}$ over a full solar cycle.

Highest accuracy in regional TEC monitoring can be achieved by combining a qualified model with actual measurements. The developed mapping algorithm approximates to the measured values in the vicinity of the subionospheric points, whereas at greater distances model values dominate. Using the rather dense network of geodetic receivers of the International GPS Service for Geodynamics (IGS) (e.g. Zumberge et al., 1994) in Europe, about 40-70 measuring points can be obtained for mapping every $30 \mathrm{~s}$. This enables the monitoring of rather dynamic ionospheric processes on large scales. Figure 3 illustrates the procedure by presenting a two-hourly map of the TEC distribution over Europe for monthly averaged TEC data of April 1995.

The accuracy of such TEC maps was checked by comparing measured $\mathrm{TEC}_{\mathrm{v}}$ data with the corresponding data

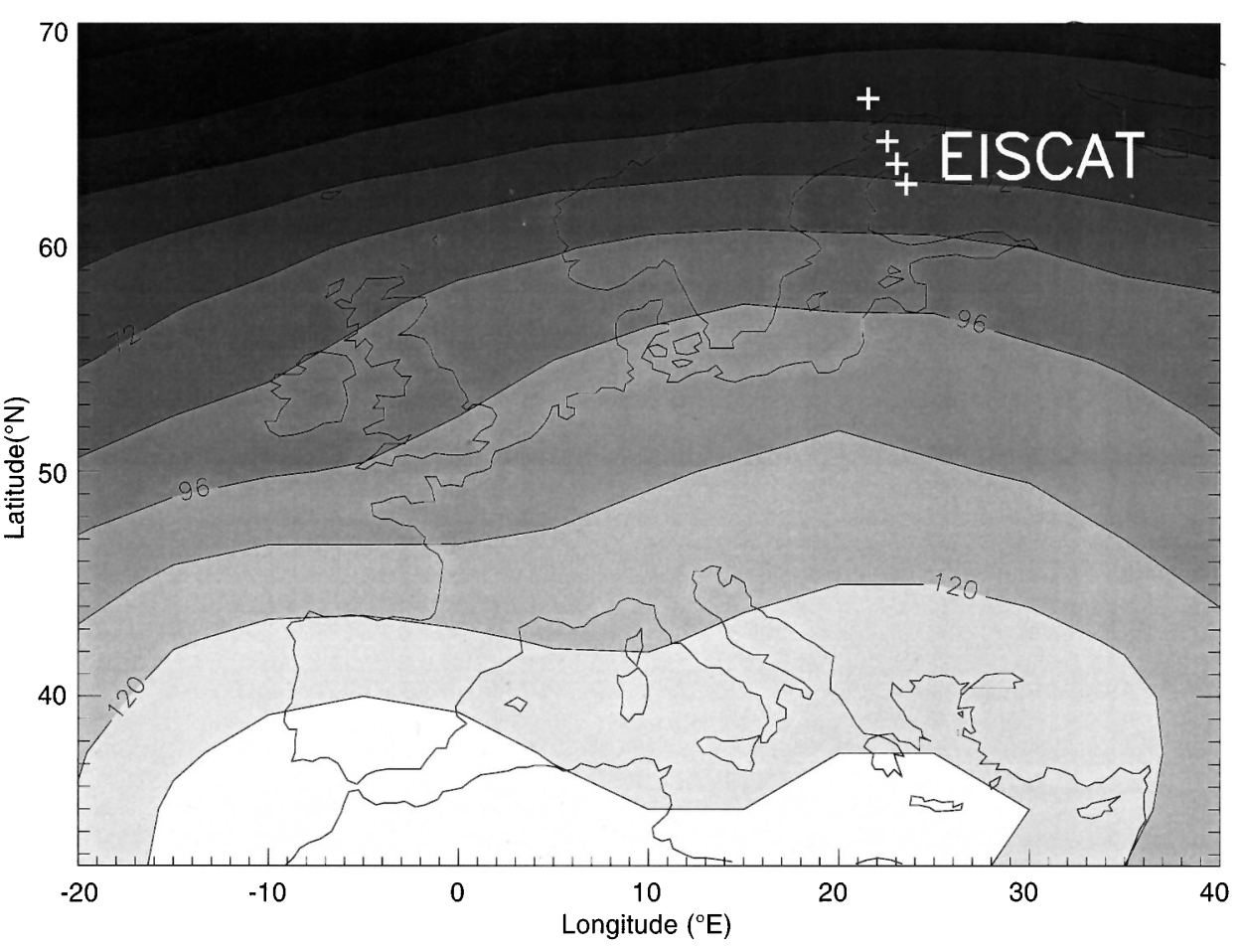

Fig. 5. TEC map and corresponding EISCAT CP3 trace on 3 February 1100 UT. The TEC contour lines are denoted in $1 \times 10^{15} \mathrm{~m}^{-2}$ and differ by $12 \times 10^{15} \mathrm{~m}^{-2}$ 

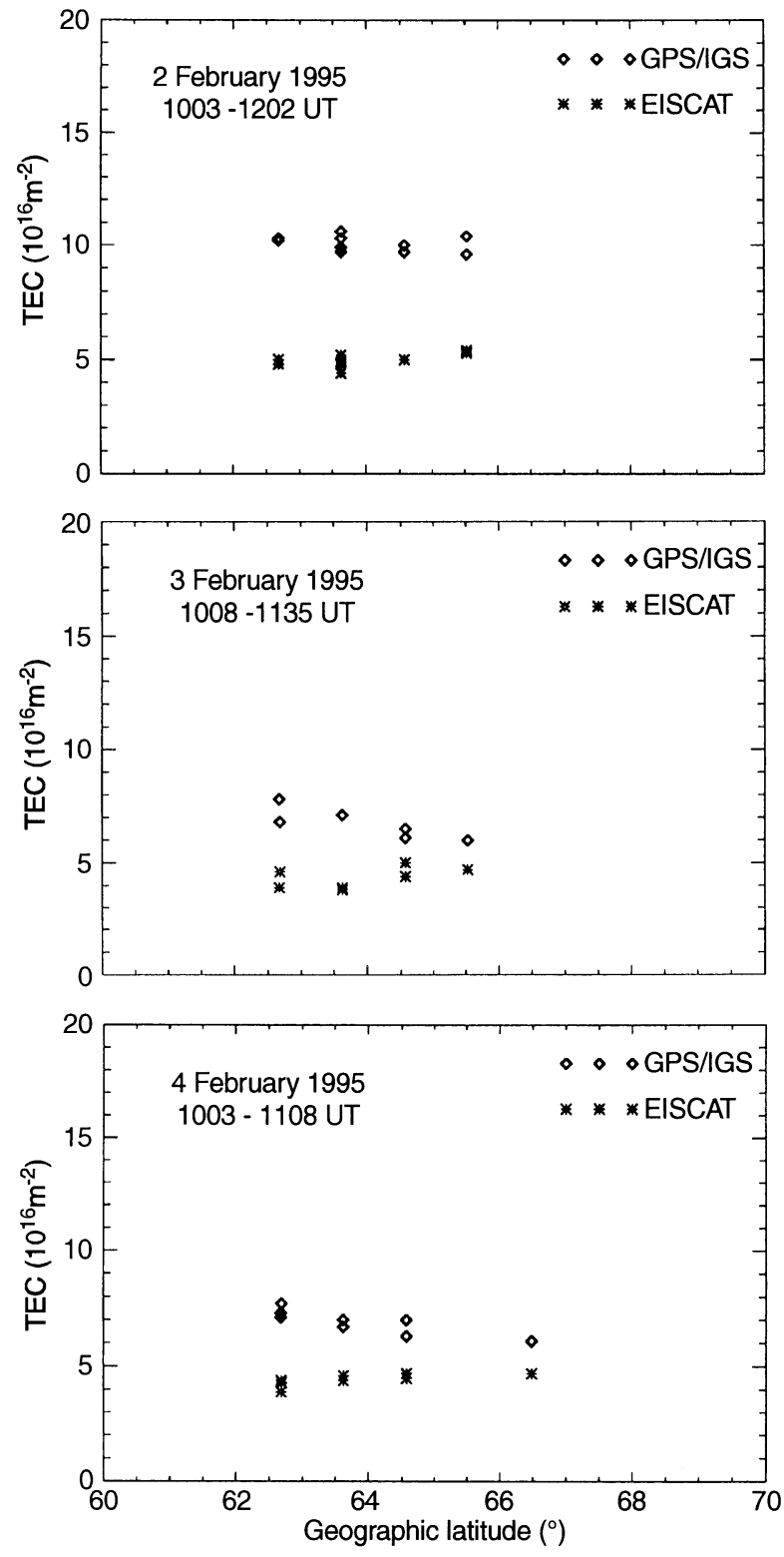

Fig. 6. Comparison of integrated and vertically mapped EISCAT CP3 data and TEC data derived from GPS measurements within 15-min time-intervals and $5^{\circ}$ distance ranges between EISCAT and GPS measuring points

derived from TEC maps. When constructing the maps, the control data were excluded. As Fig. 4 demonstrates, the RMS error for $\mathrm{TEC}_{\mathrm{v}}$ in March 1995 is in the order of $2 \times 10^{16} \mathrm{~m}^{-2}$. This result is representative also for other stations. The achieved accuracy is high enough to study large-scale ionospheric processes even under low solar activity conditions.

\section{Comparison of GPS-derived TEC with EISCAT data}

Coordinated measurements of TEC by GPS and EISCAT should indicate a high correlation between incoherentscatter-radar and TEC monitoring data in the overlap- ping region. The incoherent-scatter-radar technique can provide a lot of information about all ionospheric layers. The most important parameters measured by EISCAT in different operation modes are the electron density, the plasma temperatures and ion drift velocities as a function of height. From these basic parameters a variety of further ionospheric parameters, such as ion composition, electric-field strength, winds and electric currents, can be deduced.

The Common Programme Three (CP3) measures the electron density at different latitudes between $62^{\circ}$ and $78^{\circ} \mathrm{N}$ during a $30-\mathrm{min}$ north-south scan. Since there is an overlapping region, these scans are well suited for comparison with corresponding TEC monitoring data taken from the actual maps (Fig. 5). To compare the electrondensity data measured by EISCAT with the total columnar electron content, the CP3 data are integrated from about 150 - to about $500-\mathrm{km}$ height and then mapped with $M(\varepsilon)$ according to Eq. 4. It is evident that ionospheric topside and plasmaspheric contributions are involved in GPS/TEC data but not in EISCAT measurements. Taking into account electron densities of about $5 \times 10^{10} \mathrm{~m}^{-3}$ near $150-\mathrm{km}$ height at all selected days, the contribution of the bottomside ionosphere should be less than $4 \times 10^{15} \mathrm{~m}^{-2}$.

Thus, the difference is expected to be mainly related to the topside ionosphere above $500 \mathrm{~km}$ including the plasmaspheric content. Since the plasmaspheric electron content and its behaviour is not well known, a comparison between EISCAT and TEC-monitoring data can improve our knowledge about plasmasphere-ionosphere relationships especially at high latitudes. This is illustrated in Fig. 6 where height-integrated CP3 data are compared with the corresponding TEC data taken from the map along the CP3 scan trace. For the presentation in Fig. 6 only CP3 data with high-quality fits have been selected. During the considered measuring times subsequent scans have been included. This explains why at a fixed latitude several values with a small dispersion appear in the plot. The TEC data are deduced from subsequent TEC maps available every $10 \mathrm{~min}$ in such a way that the spatial distance between the EISCAT and GPS measuring points is less than $5^{\circ}$ and these measurements are carried out within a 15 -min interval. The corresponding EISCATCP3 trace for 3 February 1995 is shown in Fig. 5, illustrating that the map guides the EISCAT measurement by large-scale information about the horizontal structure for the ionospheric plasma.

The plots in Fig. 6 clearly indicate the contribution of the topside ionosphere and plasmasphere in the TEC data based on GPS measurements. Since the RMS mapping accuracy lies in the order of $2 \times 10^{16} \mathrm{~m}^{-2}$ (cf. Fig. 4), estimations of the plasmashperic content are still rather crude. Nevertheless, large-scale perturbation processes and related magnetosphere-ionosphere coupling are expected to be documented in the data.

The difference between TEC and EISCAT varies at the sample days 2-4 February 1995 between 1.5 and $5.5 \times 10^{16} \mathrm{~m}^{-2}$, which seems to be quite reasonable. With $A_{p}$ values ranging from 23 to 26 , the geomagnetic activity was moderate during these days. Thus the variability in 


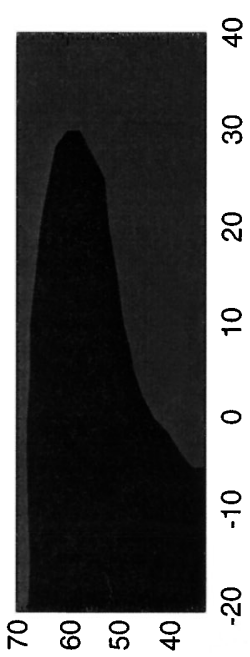

(No) өpnu!̣e 7

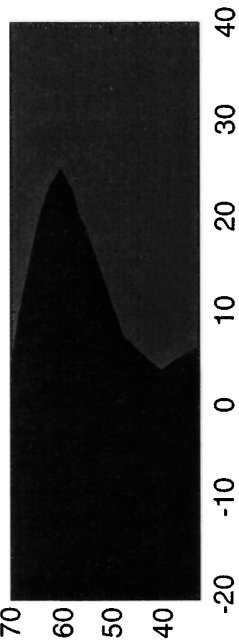

(No) әpnџ!ฺe

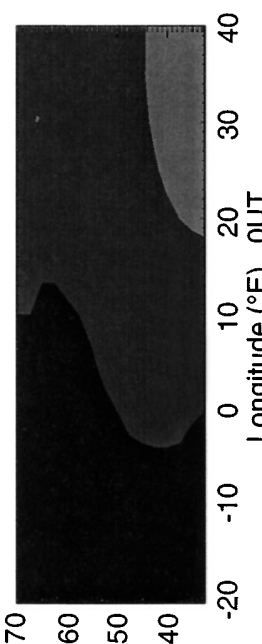

(No) әpn!!ฺ 7

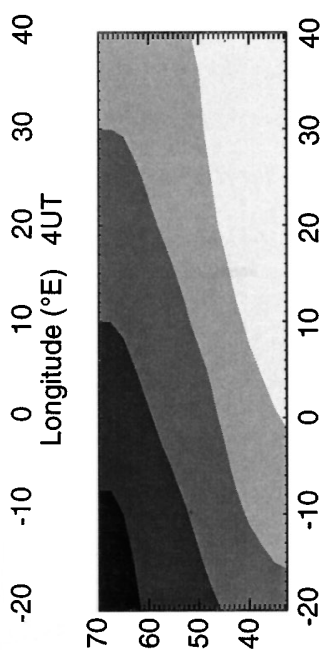

(No) әрпџ!ฺ 7

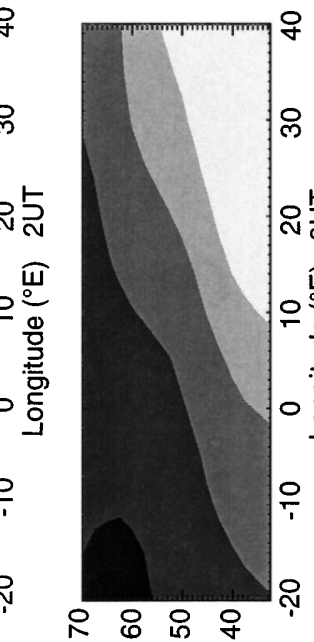

(No) әрпџ!ฺएา

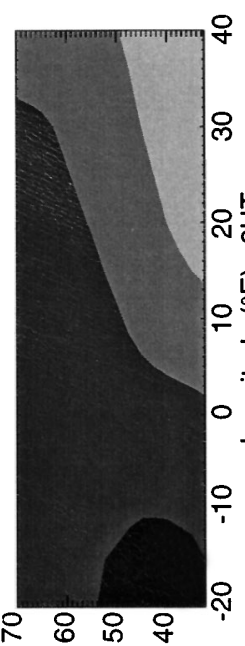

(No) epnџ!eา

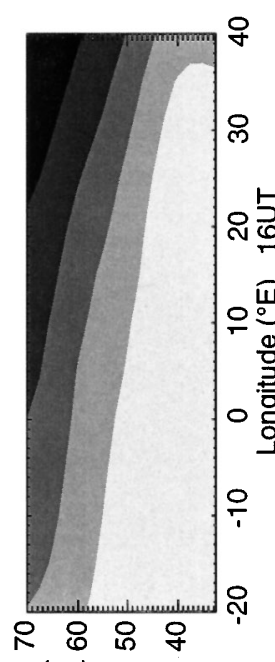

(No) өpn!!?e 7

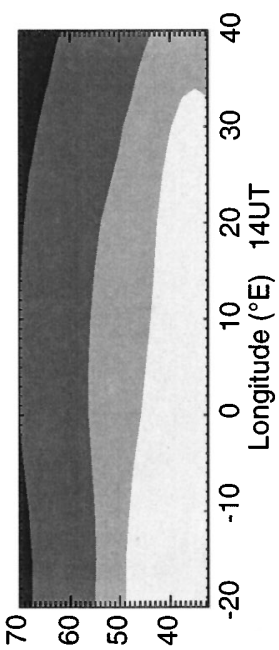

(No) әрпџ!!eך

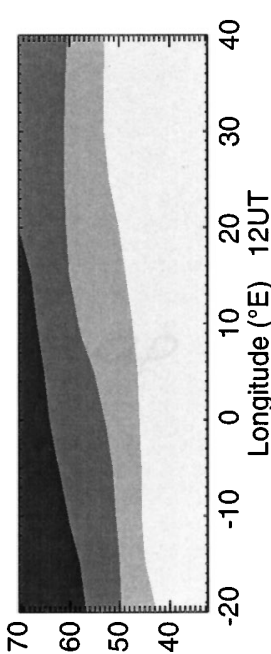

(No) əpn!!!ฺา

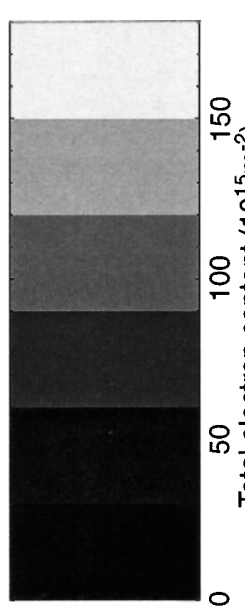

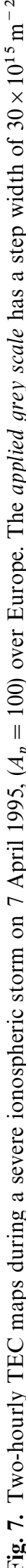


TEC difference between EISCAT and GPS data might be related to geomagnetic perturbations. The convergence of the TEC data towards higher latitudes might be interpreted by the natural reduction of the plasmaspheric contribution at high latitudes. The rather good agreement of GPS-derived TEC and EISCAT data confirms the accuracy of the former. Since the TEC-estimation algorithms are based on some simplifying assumptions, the validation of the deduced TEC data products is an important task to which EISCAT effectively contributes.

\section{Large-scale ionospheric perturbations}

At high latitudes where significant interactions between the solar wind and the Earth's ionosphere and atmosphere take place, the ionosphere is strongly influenced by precipitating particles and by large-scale electric fields of magnetospheric origin. So a number of phenomena are generated in this region which may cause severe disturbances in GPS receiving systems (e.g. Bishop et al., 1994).

In order to reduce signal degradation by ionospheric processes, a better understanding of the ionosphere and their relationships to the atmosphere and magnetosphere systems is required. In particular, the influence of significant short-term irregularities, detected as amplitude or phase scintillations, and strong large-scale variations of the plasma density should be studied in more detail. The combination of detailed EISCAT measurements with TEC maps of high temporal and spatial resolution should provide new insights into the complex behaviour of the ionosphere.

Although studied for more than six decades, ionospheric storms are not yet fully understood. This is mainly due to the complex interaction of various processes in the magnetosphere, thermosphere and ionosphere on a global scale lasting several days. Experimental studies have to take into account this large-scale complexity. Regional or global maps of TEC in combination with other ionospheric probing techniques such as EISCAT or vertical sounding are well suited to study some open questions related to the mechanism of ionospheric storms. Thus, for instance, the global response of the ionospheric ionization to electric fields or neutral winds may be studied effectively. If electric fields are assumed to play an important role during the onset phase of mid-latitude ionospheric storms (e.g. Jakowski et al., 1990, 1992), a simultaneous increase in the ionospheric ionization (TEC) should be observed down to lower latitudes. Equatorwards-blowing winds or other propagating phenomena (AGW), which can contribute to the positive storm phase, need a few hours (e.g. Prölss, 1995; Prölss et al., 1991) to propagate to the equator, leading to a delayed increase in ionization along their way towards lower latitudes. As has been shown by Jakowski et al. (1992), EISCAT data provide valuable information (electric fields, currents and atmospheric heating) to discuss ionospheric perturbation phenomena. Figure 7 provides two-hourly snapshots of the TEC over Europe on 7 April 1995. In the course of the geomagnetic storm on 6-7 April the geomagnetic activity increased rapidly from $K_{p}=0.3(15-18 \mathrm{UT})$ on 6 April 1995 to 5.7 (03-06 UT) on 7 April 1995.

As Fig. 7 shows, the storm-induced ionization enhancement starts in the early morning of 7 April and leads to an increase in TEC over the whole latitude range in view (see also Fig. 3 for comparison). The excess production of ionospheric plasma in the auroral zone lasts up to about 2000 UT. Between 50 and $60^{\circ} \mathrm{N}$, a well-pronounced electron-density trough appears at the end of the positive phase around 2000 UT. The subsequent maps which are not shown here indicate a well-pronounced negative storm phase which moves from the auroral zone equatorwards. According to current theories this can be explained by an equatorward transport of composition changes consisting of an enrichment of $\mathrm{N}_{2}$ and $\mathrm{O}_{2}$ molecules (e.g. Prölss, 1995; Prölss et al., 1991). A more detailed discussion of such processes is beyond the scope of this paper.

\section{Summary and conclusions}

It has been shown that the coordinated analysis of GPSderived TEC maps and simultaneously obtained EISCAT data can contribute both to improve positioning by GPS as well as to explore large-scale ionospheric processes. So the derived regional TEC maps over Europe can be validated by using EISCAT (especially CP3) data. Such TEC maps can be used in GPS navigation to reduce ionospheric propagation errors. EISCAT studies of smallscale and short-term irregularities contribute also to the understanding of ionospheric-induced GPS-signal degradations at high latitudes.

On the other hand, GPS-derived TEC maps with RMS accuracies of $2 \times 10^{16} \mathrm{~m}^{-2}$ or better can effectively be used in studying large-scale ionospheric processes. Comparing the maps with corresponding EISCAT observations, conclusions about the plasmaspheric content and plasmasphere-ionosphere coupling can be drawn. The combination of EISCAT data with TEC maps should be a powerful tool for studying ionospheric storms, to have a better understanding of generation mechanisms (EISCAT) and propagation processes (TEC map).

Acknowledgements. The authors express their deep thanks to the colleagues from the IGS community who made available the highquality GPS data sets. We thank also K. Schlegel for providing EISCAT data and E. Putz and P. Spalla for providing Faraday rotation data. The research was supported by the German Agency of Space Activities (DARA) under contract 50 Y19202.

Topical Editor D. Alcaydé thanks R. Leitinger and another referee for their help in evaluating this paper.

\section{References}

Bishop, G. J., T. W. Bullett, and E. A. Holland, GPS Measurement of L-Band Scintillation and TEC in the Northern Polar Cap Ionosphere at Solar Maximum, Proc. Int. Beacon Sat. Symp. (Ed. L. Kersley), Aberystwyth, UK, 11-15 July 1994, pp. 29-32, 1994.

Coco, D., GPS-Satellites of Opportunity for Ionospheric Monitoring, GPS world, 47-50, October 1991

Davies, K., Remote sensing of the ionosphere using satellite radio beacons, Indian J. Radio Space Phys., 20, 356-367, 1991. 
Jakowski, N., and A. Jungstand, Modelling the Regional Ionosphere by Using GPS Observations, Proc. Int. Beacon Sat. Symp. (Ed. L. Kersley), University of Wales, Aberystwyth, 11-15 July 1994 pp. 366-369, 1994

Jakowski, N., and E. Paasch, Report on the observations of the total electron content of the ionosphere in Neustrelitz GDR from 1976 to 1980, Ann. Geophysicae, 2, 501-504, 1984.

Jakowski, N., E. Putz, and P. Spalla, Ionospheric storm characteristics deduced from satellite radio beacon observations at three European stations, Ann. Geophysicae, 8, 343-352, 1990.

Jakowski, N., A. Jungstand, K. Schlegel, H. Kohl, and K. Rinnert, The ionospheric response to perturbation electric fields during the onset phase of geomagnetic storms. Can. J. Phys., 70, 575-581, 1992.

Prölss, G. W., Ionospheric F-Region Storms, in Handbook of Atmospheric Electrodynamics, Vol. 2, ed. Volland, CRC Press, Boca Raton, Fla, 195-248, 1995.
Prölss, G. W., L. H. Brace, H. G. Mayr, G. R. Carignan, T. L. Killeen, and J. A. Klobuchar, Ionospheric Storm Effects at Subauroral Latitudes: A Case Study, J. Geophys. Res., 96, 1275-1288, 1991.

Sardon, E., A. Rius, and N. Zarraoa, Estimation of the receiver differential biases and the ionospheric total electron content from Global Positioning System observations, Radio Sci., 29, 577-586, 1994.

Wilson, B. D., A. J. Manucci, and Ch. D. Edwards, Subdaily northern hemisphere ionospheric maps using an extensive network of GPS receivers, Radio Sci., 30, 639-648, 1995.

Zarraoa, N., and E. Sardon, Test of GPS for permanent ionospheric TEC monitoring at high latitudes, Ann. Geophysicae, 14, 11-19, 1996.

Zumberge, J., R. Neilan, G. Beutler, and W. Gurtner, The International GPS-Service for Geodynamics-Benefits to Users., Proc. ION GPS-94, Salt Lake City, September 20-23, 1994. 